\title{
Field and Laboratory Evaluation of Bermudagrass Germplasm for Cold Hardiness and Freezing Tolerance
}

\author{
Jeffrey C. Dunne, Tan D. Tuong, David P. Livingston, W. Casey Reynolds, and Susana R. Milla-Lewis`
}

\begin{abstract}
Bermudagrass [Cynodon spp. (L.) Rich.] is a high-quality, durable turfgrass with excellent heat and drought tolerance. However, its lack of freezing tolerance limits its use in the transition zone. The development of cultivars with enhanced freezing tolerance would constitute a significant improvement in the management of bermudagrass in this region and could extend its area of adaptation further north. There has been substantial work on screening of commontype bermudagrass [Cynodon dactylon (L.) Pers.] germplasm for freezing tolerance, but not for the African (Cynodon transvaalensis Burtt-Davy) germplasm. The purpose of this research was to conduct multiyear field testing and laboratory-based freezing test evaluations of winter hardiness and freezing tolerance, respectively, of an African and common bermudagrass germplasm collection. A high level of cold hardiness was observed among the germplasm in this study. In field evaluations, plant introductions (PIs) PI 290905, PI 647879, PI 255447, PI 289923, and PI 615161 were the top performers, having consistently greater spring green-up and reduced winterkill compared with 'Patriot', 'Tifsport', 'Quickstand', and 'Tifway', though not always significantly. A comparison between field-based ratings and calculated lethal temperatures for $50 \%$ death $\left(\mathrm{LT}_{50}\right)$ from laboratory-based freezing tests showed significant correlations of -0.26 and -0.24 for spring green-up and winterkill, respectively, suggesting that these controlled freeze experiments could be used to prescreen materials prior to field testing. Overall, results indicate that some of the PIs evaluated in this study can be used as additional sources of cold hardiness in bermudagrass breeding.
\end{abstract}

J.C. Dunne and S.R. Milla-Lewis, Dep. of Crop Science, Campus Box 7620, North Carolina State Univ., Raleigh, NC, 27695-7620; T.D. Tuong and D.P. Livingston, Dep. of Agriculture and Dep. of Crop Science, North Carolina State Univ., Raleigh, NC 27695; W.C. Reynolds, Turfgrass Producers International, 444 E. Roosevelt Rd., Suite 346, Lombard, IL 60148. Received 8 Nov. 2017. Accepted 19 Sept. 2018. `Corresponding author (susana_milla-lewis@ncsu.edu). Assigned to Associate Editor Emily Merewitz.

Abbreviations: $\mathrm{LT}_{50}$, lethal temperature for 50\% death; NPGS, National Plant Germplasm System; PI, plant introduction.

B ERMUdagrass [Cynodon spp. (L.) Rich.] is widely used in golf courses, athletic fields, and home lawns in the southern United States for the superior turf quality and excellent durability the species exhibits. Although the grass is considered to have excellent heat and drought tolerance, its ability to survive freezing temperatures is limited (Beard, 1973), and bermudagrasses periodically sustain winter injury in the transition zone (Anderson et al., 2002; Richardson et al., 2014). The development of cultivars with enhanced adaptation to freezing temperatures would constitute a significant improvement in the management of bermudagrass for the region. Bermudagrass reaches limitations of adaptation where low-temperature stress causes frequent plant mortality (Gatschet et al., 1994; Taliaferro, 1995; Anderson et al., 2007; Rutledge et al., 2009). The loss of a turfgrass stand can produce substantial costs for reestablishment (Dunn et al., 1999; Munshaw et al., 2006). Therefore, the development of bermudagrass cultivars with improved freeze tolerance and superior turf quality has become a goal for bermudagrass breeding programs, considering its lower tolerance to freezing temperatures compared with zoysiagrass (Zoysia spp.) (DiPaola and Beard, 1992).

Published in Crop Sci. 59:392-399 (2019).

doi: 10.2135/cropsci2017.11.0667

(C) Crop Science Society of America | 5585 Guilford Rd., Madison, WI 53711 USA This is an open access article distributed under the CC BY-NC-ND license (http://creativecommons.org/licenses/by-nc-nd/4.0/). 
Cultivar selection is considered one of the most important steps for the success of bermudagrass turf, especially in the transition zone where both cool-season grasses and warm-season grasses are not equally adept at surviving the extreme temperatures in the summer and winter months (Patton et al., 2008; Giolo et al., 2013; Rimi et al., 2013). Bermudagrass cultivars vary in their inherent ability to tolerate extreme low temperatures (Ahring and Irving, 1969; Anderson et al., 2003; Taliaferro et al., 2004) and in coming back from dormancy in the spring (Munshaw et al., 2006). Evidence of variation among bermudagrass cultivars can be seen in the National Turfgrass Evaluation Program. Seeded cultivars 'Yukon' and 'Riviera' and vegetatively propagated cultivars 'Midlawn' and 'Northbridge' ranked among the highest in spring green-up and lowest in percentage winterkill (NTEP, 2012). Conversely, the seeded cultivar 'Princess 77' and the vegetatively propagated cultivar 'Tifway' were lowest in spring green-up and the highest in percentage winterkill (NTEP, 2012).

In addition to field evaluations, controlled freezing tests have been developed to separate common and hybrid bermudagrass [Cynodon dactylon (L.) Pers. $\times$ Cynodon transvaalensis Burtt Davy] cultivars on the basis of lethal freezing temperature for $50 \%$ mortality $\left(\mathrm{LT}_{50}\right)$ (Anderson et al., 1993, 2002, 2003, 2007; Anderson and Taliaferro, 2002). The objective behind freezer-based screening methods is to quickly identify genotypic differences in freezing survivability in hopes to make selections that reflect or predict field-based performance. Dunn et al. (1999), Patton and Reicher (2007), and Hinton et al. (2012) determined a correlation between field-based winter injury and the controlled freezer-based $\mathrm{LT}_{50}$ values in zoysiagrass. Effective identification of predictors, like $\mathrm{LT}_{50}$ values, for field performance could result in a more efficient means for selection and cultivar development for cold hardiness in bermudagrass. Therefore, the objectives of this research were (i) to evaluate bermudagrass germplasm for cold hardiness in the field, (ii) to evaluate these materials for freezing tolerance in a controlled laboratory environment, (iii) to determine correlations between the evaluations in the field and the controlled laboratory environment, and (iv) to identify new materials, specifically from the pool of African plant introductions (PIs), to be used in the development and advancement of winter hardiness breeding populations in bermudagrass.

\section{MATERIALS AND METHODS Plant Materials}

A total of 40 bermudagrass genotypes were selected for the study, including 16 African bermudagrass (C. transvaalensis) PIs from the National Plant Germplasm System (NPGS; S9 Germplasm Repository, Griffin, GA). Additionally, 11 common bermudagrass (C. dactylon) accessions obtained from NPGS (Griffin, GA), nine from the University of Georgia bermudagrass breeding program (Tifton, GA), and four commercially available controls (Tifway, Tifsport, Patriot, and Quickstand) varying in cold hardiness (Anderson et al., 2007) were included in the study (Table 1).

\section{Field Cold Hardiness Evaluations}

A cold hardiness field trial, consisting of 40 entries (Table 1), was planted in a randomized complete block design with three replications in spring 2010 at the Lake Wheeler Turfgrass Field Laboratory (Raleigh, NC). Nine plugs of each genotype were planted in $0.84-\mathrm{m}^{2}$ plots $(0.91 \times 0.91 \mathrm{~m})$ on an Appling (fine,

Table 1. List of bermudagrass entries planted at the Lake Wheeler Turfgrass Field Laboratory (Raleigh, NC) in 2010 to evaluate field winter survival and spring green-up.

\begin{tabular}{|c|c|}
\hline Species & Source \\
\hline \multicolumn{2}{|l|}{ C. dactylon } \\
\hline T-642 & UGA \\
\hline $\mathrm{T}-643$ & UGA \\
\hline $\mathrm{T}-726$ & UGA \\
\hline $\mathrm{T}-729$ & UGA \\
\hline $\mathrm{T}-730$ & UGA \\
\hline $\mathrm{T}-732$ & UGA \\
\hline $\mathrm{T}-733$ & UGA \\
\hline $\mathrm{T}-734$ & UGA \\
\hline $\mathrm{T}-737$ & UGA \\
\hline PI 212293 & GRIN \\
\hline PI 220588 & GRIN \\
\hline PI 224141 & GRIN \\
\hline PI 224143 & GRIN \\
\hline PI 224694 & GRIN \\
\hline PI 246600 & GRIN \\
\hline PI 251108 & GRIN \\
\hline PI 251109 & GRIN \\
\hline PI 251809 & GRIN \\
\hline PI 255442 & GRIN \\
\hline PI 255447 & GRIN \\
\hline Quickstand & NCSU \\
\hline \multicolumn{2}{|c|}{ C. transvaalensis } \\
\hline PI 286584 & GRIN \\
\hline PI 289922 & GRIN \\
\hline PI 289923 & GRIN \\
\hline PI 290812 & GRIN \\
\hline PI 290813 & GRIN \\
\hline PI 290872 & GRIN \\
\hline PI 290894 & GRIN \\
\hline PI 290897 & GRIN \\
\hline PI 290905 & GRIN \\
\hline PI 291981 & GRIN \\
\hline PI 491560 & GRIN \\
\hline PI 615161 & GRIN \\
\hline PI 647878 & GRIN \\
\hline PI 647879 & GRIN \\
\hline PI 647880 & GRIN \\
\hline PI 647881 & GRIN \\
\hline \multicolumn{2}{|c|}{ C. transvaalensis $\times$ C. dactylon } \\
\hline Tifway $\ddagger$ & NCSU \\
\hline Tifsportł & NCSU \\
\hline Patriot§ & NCSU \\
\hline
\end{tabular}

† UGA, University of Georgia; GRIN, Germplasm Resources Information Network; NCSU, North Carolina State University germplasm collection.

‡ Somatic chromosome count: $2 n=3 x=27$.

$\S$ Somatic chromosome count: $2 n=4 x=36$. 
kaolinitic, thermic Typic Kanhapludults) fine sandy loamCecil (fine, kaolinitic, thermic Typic Kanhapludults) sandy loam (NRCS, 2013). The plots were mowed at $5.1 \mathrm{~cm}$ using a rotary mower, and irrigation was applied to limit drought stress. Three applications of a 26-0-13 (N- $\left.\mathrm{P}_{2} \mathrm{O}_{5}-\mathrm{K}_{2} \mathrm{O}\right)$ (Polyon, Harrell's) were applied at a $\mathrm{N}$ rate of $48.8 \mathrm{~kg} \mathrm{ha}^{-1}$ in each year of the study. The plots were evaluated for spring green-up and winter survival each spring from 2011 to 2015. Spring green-up was evaluated on a 1-to-9 scale, where 1 represents no green color and 9 represents full green plots, with ratings taken at the beginning of April. Similarly, winter survival was evaluated on a 1-to-9 scale, where 1 represents complete winterkill and 9 represents full green plots with ratings taken mid-May. In the literature, this is typically reported as winterkill. In order to avoid confusion and to parallel spring green-up ratings, winterkill will be referred to as winter survival.

\section{Controlled-Environment Freeze Evaluations and Field Correlations}

According to the methods suggested by Anderson et al. (2007), a Classen gear-drive sod cutter with a $45.7-\mathrm{cm}$ blade (Schiller Grounds Care) was used to strip sod from each field plot in September 2015. Plugs with 2.54-cm diameter were extracted from the sod and placed in 2.54-cm cone-tainers containing sterile potting soil (Farfard Growing Mix 2, Sun Gro Horticulture). Plots were stripped to ensure a consistent soil source in each cone-tainer. Plugs were allowed to grow in the greenhouse at a stable temperature of $27^{\circ} \mathrm{C}$ for $6 \mathrm{wk}$. Plugs were fertilized twice in the 6-wk growth period using a water-soluble 24-8-16 $\left(\mathrm{N}-\mathrm{P}_{2} \mathrm{O}_{5}-\mathrm{K}_{2} \mathrm{O}\right.$ ) fertilizer at a $\mathrm{N}$ rate of $4.9 \mathrm{~g} \mathrm{~m}^{-2}$ (Miracle-Gro All Purpose Plant Food, The Scott's Company). Plugs maintained at a $2.54-\mathrm{cm}$ height were mowed weekly with handheld electric grass shears.

The number of entries from the field was reduced from 40 to 22 due to freezer capacity limitations. Two controls, Patriot and Tifway, were included and the remaining 20 entries were selected to reflect the range in cold hardiness from spring green-up and winter survival evaluations. The experimental design for the controlled freeze evaluations was a randomized complete block design consisting of three trial runs, four selected temperatures, two replications, and four cone-tainers per replication (subplots) from the selected 22 entries. Prior to the freezing evaluations, a pilot study was conducted with Patriot and Tifway only. The purpose of the pilot study was (i) to standardize the freezing protocol and (ii) to determine the temperature range for optimal $\mathrm{LT}_{50}$ evaluations. Based on the pilot study, four temperatures $\left(-4,-5,-6\right.$ and $\left.-7^{\circ} \mathrm{C}\right)$ were selected to provide a range of responses. The freezing protocol was done in accordance with previously conducted studies with minor modifications (Anderson et al., 1993, 2003, 2007; Kimball et al., 2017). Plugs were subjected to cold acclimation at $13^{\circ} \mathrm{C}$ under a consistent light-emitting diode (LED) growth chamber providing a $12-\mathrm{h}$ photoperiod at $300 \mu \mathrm{mol} \mathrm{m} \mathrm{m}^{-2} \mathrm{~s}^{-1}$ for a week and then moved to a $3^{\circ} \mathrm{C}$ growth chamber with a $12-\mathrm{h}$ photoperiod at $300 \mu \mathrm{mol} \mathrm{m} \mathrm{m}^{-2} \mathrm{~s}^{-1}$ for one more week before freezing. For freezing tests, ice shavings were placed on the soil of each plug to promote freezing and avoid supercooling. Each replication was placed in individual plastic bags to minimize desiccation during freezing. Six thermocouples were placed within the canopy and soil of random plugs to record plant and soil temperatures during freezing tests.

Independent experiments were conducted for the four different freezing temperatures $\left(-4,-5,-6\right.$, and $\left.-7^{\circ} \mathrm{C}\right)$ with three individual runs of the freezing test per temperature during the winter of 2015-2016. Plants were placed in freezers, and the ambient air temperature was immediately lowered to $-3^{\circ} \mathrm{C}$ for $18 \mathrm{~h}$ to allow for latent heat to dissipate from the soil. The temperature was then decreased at a rate of $1^{\circ} \mathrm{C} \mathrm{h}^{-1}$ until reaching the target freezing temperature, which was maintained for $3 \mathrm{~h}$ in accordance to Kimball et al. (2017). The temperature was then increased at a rate of $2^{\circ} \mathrm{C} \mathrm{h}^{-1}$ until reaching $15^{\circ} \mathrm{C}$. Plants were then placed back in a $27^{\circ} \mathrm{C}$ temperature-controlled greenhouse for evaluation.

\section{Data Analysis}

Analysis of field data was performed using Proc GLM in SAS version 9.4 (SAS Institute, 2013). Given the experimental design, the entries were tested against the appropriate error term, producing an exact $F$ test. Mean separation was performed according to Fisher's protected LSD values at a significance level of $\alpha=0.05$ to determine rankings and significance between entries.

For freezing evaluations, data were collected on a binary 0 (dead) to 1 (survival) scale and were evaluated over the course of $3 \mathrm{wk}$ in order to determine the $\mathrm{LT}_{50}$ of each genotype. These ratings were taken weekly on each plug to determine the survivability across the temperature gradient. Since some of the plugs either wilted immediately after freezing but recovered after the $3 \mathrm{wk}$, or had surviving green tissue after the freeze event but did not survive after $3 \mathrm{wk}$, the last rating date of binary values was subject to a logistic regression analysis to determine 50\% surviving probability for each genotype. Evaluations for $-7^{\circ} \mathrm{C}$ were excluded from the analysis, as no plugs survived this temperature. The LOGISTIC procedure was used in SAS 9.4 and a stepwise selection method was used to select the most parsimonious model for $\mathrm{LT}_{50}$ values. In order to bypass problems with quasi-complete separation, in instances where quasi-complete separation was detected, values were added to classes where an event was not present in order to obtain estimates. For example, if a genotype had all plants survive at $-4^{\circ} \mathrm{C}$, an additional observation was included to represent concordance with a dead ("0") sample. When the convergence criteria had been met and the selection criteria had limited the model to optimize sensitivity and specificity according to the receiver operating characteristic curve, the maximum likelihood estimates for the model were output and the $\mathrm{LT}_{50}$ values were calculated. The $\mathrm{LT}_{50}$ calculations were based on the probability of freezing survival $\left(P_{i}\right)$ using a logistic regression model:

$$
P_{i}=\frac{1}{1+e^{-\left(\beta_{0}+\beta_{1} X_{1}+\ldots+\beta_{k} X_{k i}\right)}}
$$

where $\beta_{0}$ is the intercept, and $\beta_{1}$ is the estimate for the occurrence of the $X_{1}$ parameter for all estimates and parameters $\beta_{k} X_{k i}$ based on the effects reference and selection criteria. Patriot was used as the reference in design variable coding because of its relative cold hardiness. To obtain differences among $\mathrm{LT}_{50}$ values, odds ratio estimates were obtained for comparisons 
Table 2. ANOVA for the response variables spring green-up and winterkill from field data collected at the Lake Wheeler Turfgrass Field Laboratory in Raleigh, NC, in spring from 2011 to 2015.

\begin{tabular}{|c|c|c|c|c|c|}
\hline \multirow[b]{2}{*}{ Source } & \multirow[b]{2}{*}{ df } & \multicolumn{2}{|c|}{ Spring green-up } & \multicolumn{2}{|c|}{ Winterkill } \\
\hline & & $F$ value & $P>F$ & $F$ value & $P>F$ \\
\hline Year & 3 & 19.16 & $<0.0001$ & 123.12 & $<0.0001$ \\
\hline Genotype & 39 & 29.34 & $<0.0001$ & 37.48 & $<0.0001$ \\
\hline Replication & 2 & 4.4 & 0.0133 & 15.34 & $<0.0001$ \\
\hline Year $\times$ replication & 6 & 1.85 & 0.0905 & 0.21 & 0.9722 \\
\hline Genotype $\times$ replication & 78 & 2.6 & $<0.0001$ & 3.33 & $<0.0001$ \\
\hline Year $\times$ genotype & 117 & 5.53 & $<0.0001$ & 5.98 & $<.0001$ \\
\hline
\end{tabular}

between the test genotype and the reference genotype, Patriot, at a significance level of $\alpha=0.05$.

In order to detect a correlation between field response and freezing evaluations, spring green-up and winter survival values from the field were compared with the $\mathrm{LT}_{50}$ values calculated from the freezer-based controlled environment tests. The analysis was done using the CORR procedure in SAS 9.4.

\section{RESULTS}

\section{Field Cold Hardiness Evaluations}

The ANOVA suggests a strong year $\times$ genotype interaction for both spring green-up and winterkill (winter survival) ratings (Table 2). Therefore, the results are presented for the genotypes separated by year. Additionally, evaluations taken in 2012 were not included in the results due to the high relative air temperatures and no separation in genotypes for that year (Fig. 1). The daily low temperatures indicated that 2012-2013 recorded the warmest average temperatures, whereas 2010-2011 had the most days below freezing and 2013-2014 was the coldest on average. Furthermore, temperature effects within each year can be seen in the spring green-up and winter survival (Fig. 2). In 2014, the coldest year, ratings for both spring green-up and winter survival were the lowest on average across genotypes. In 2013, winter survival was the highest recorded. The remaining two years (2011 and 2015) had the greatest spring green-up; however, they also had the greatest variability in winter survival among the genotypes. In addition, daily low temperatures during these 2 yr were not as consistent as in 2012-2013.

The top-performing genotypes for spring green-up across years were PI 290905, PI 647879, PI 255447, PI 289923, and PI 615161 (Fig. 2). However, PI 647880

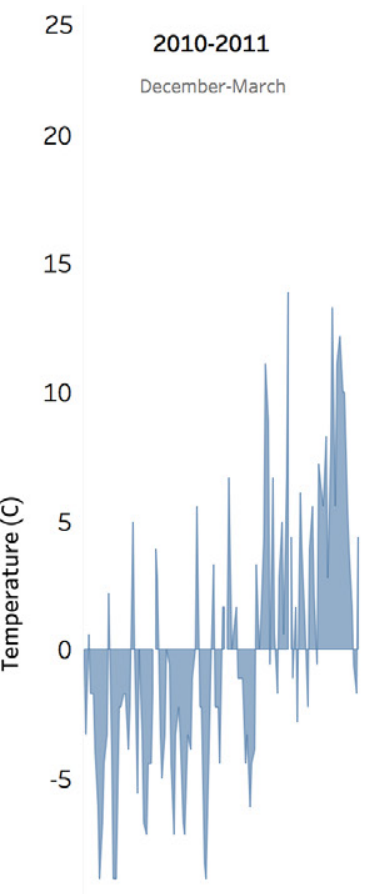

$-10$

$-15$

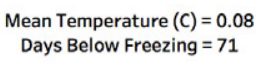

$-20$
2011-2012

December-March
2012-2013

December-March
2013-2014

December-March
2014-2015

December-March
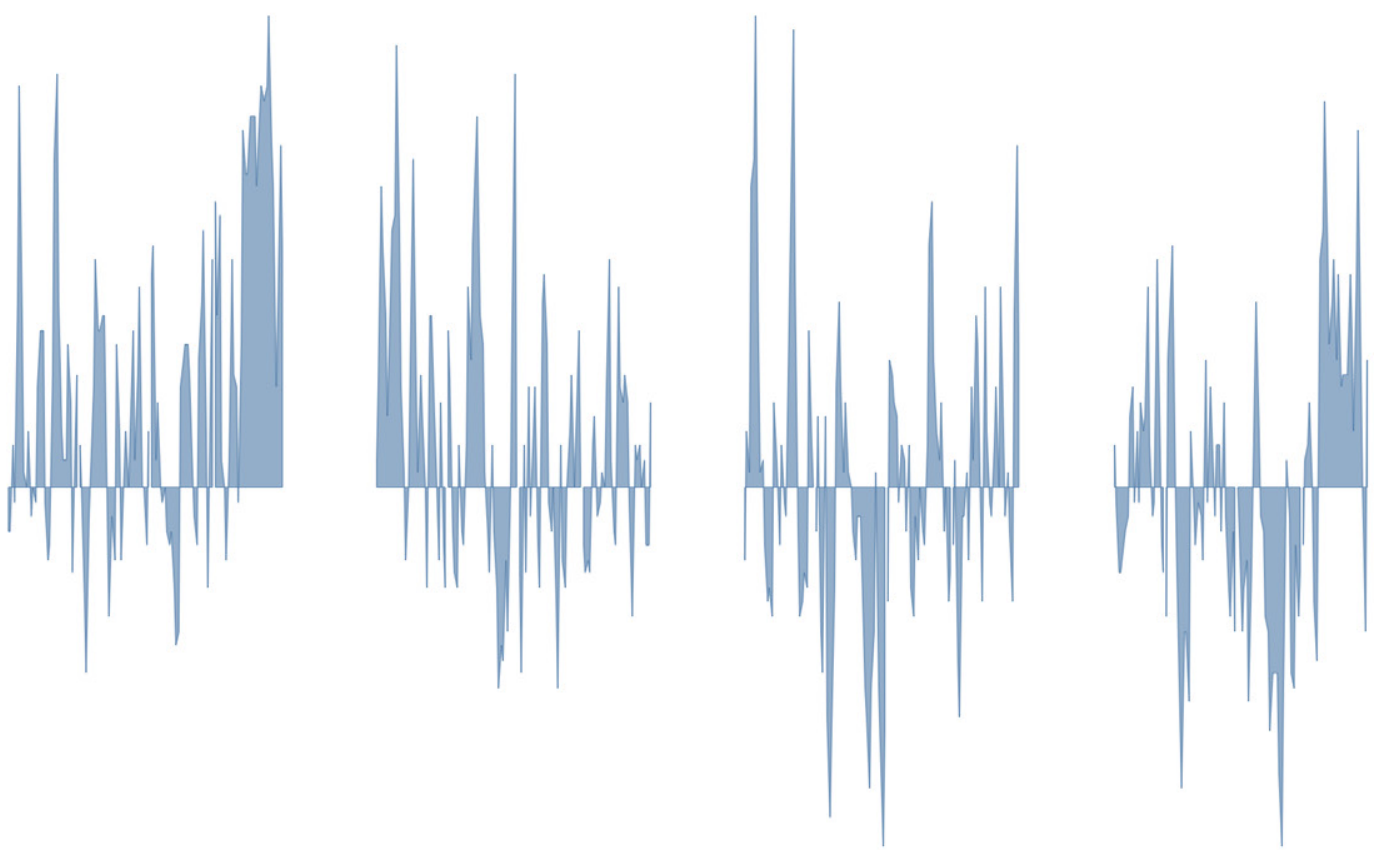

Mean Temperature $(C)=4.00$

Mean Temperature $(C)=1.80$

Mean Temperature $(C)=0.05$ Days Below Freezing $=64$

Mean Temperature $(C)=0.38$ Days below freezing $=63$

Fig. 1. Minimum daily temperatures $\left({ }^{\circ} \mathrm{C}\right)$ collected from 2010 to 2015 from the Lake Wheeler Turfgrass Field Laboratory in Raleigh, NC. 
Spring Green-Up
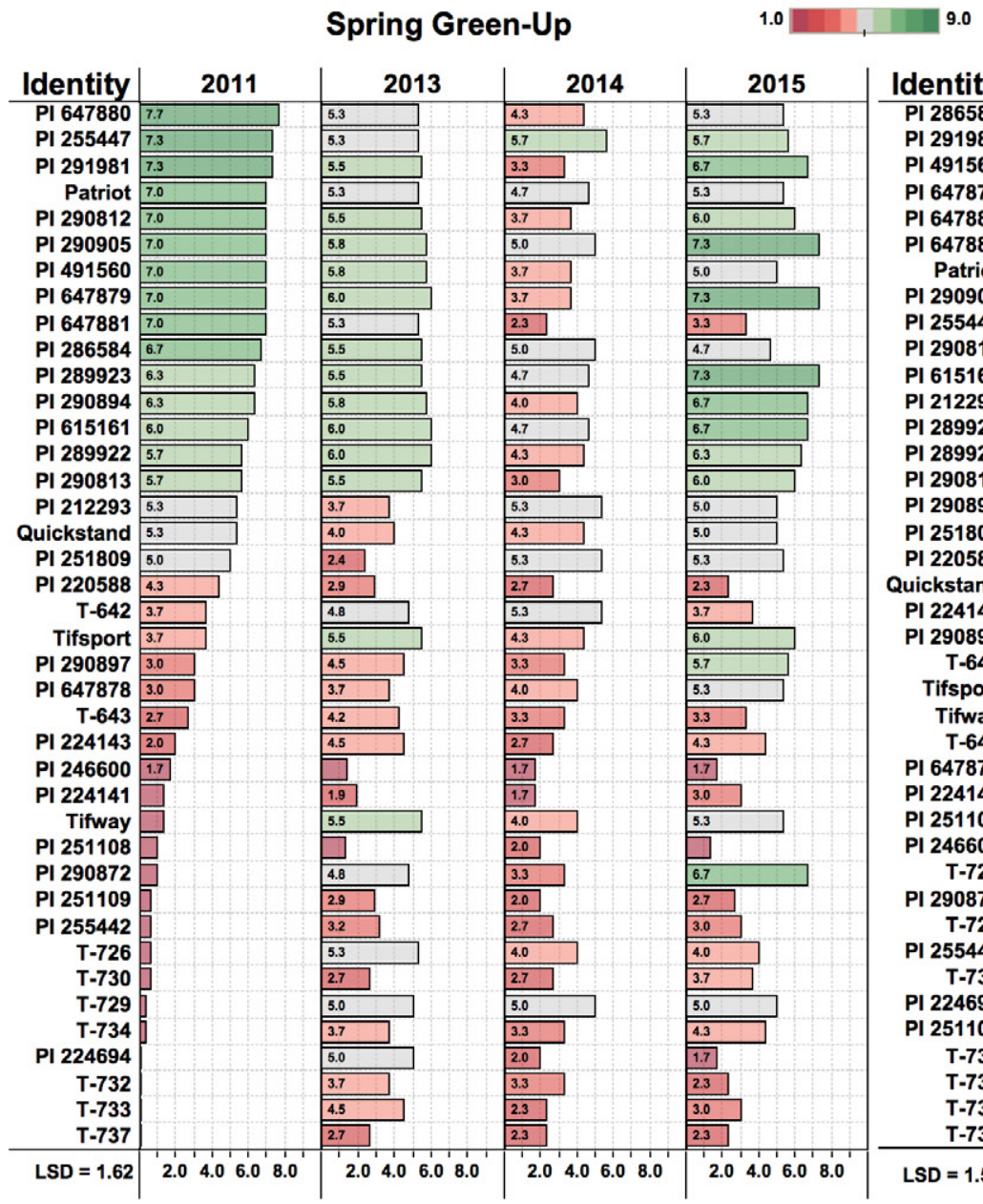

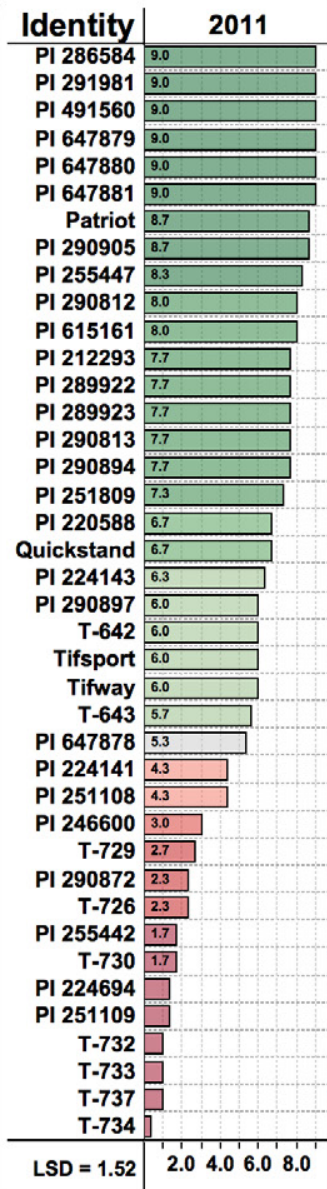

Winter Survival

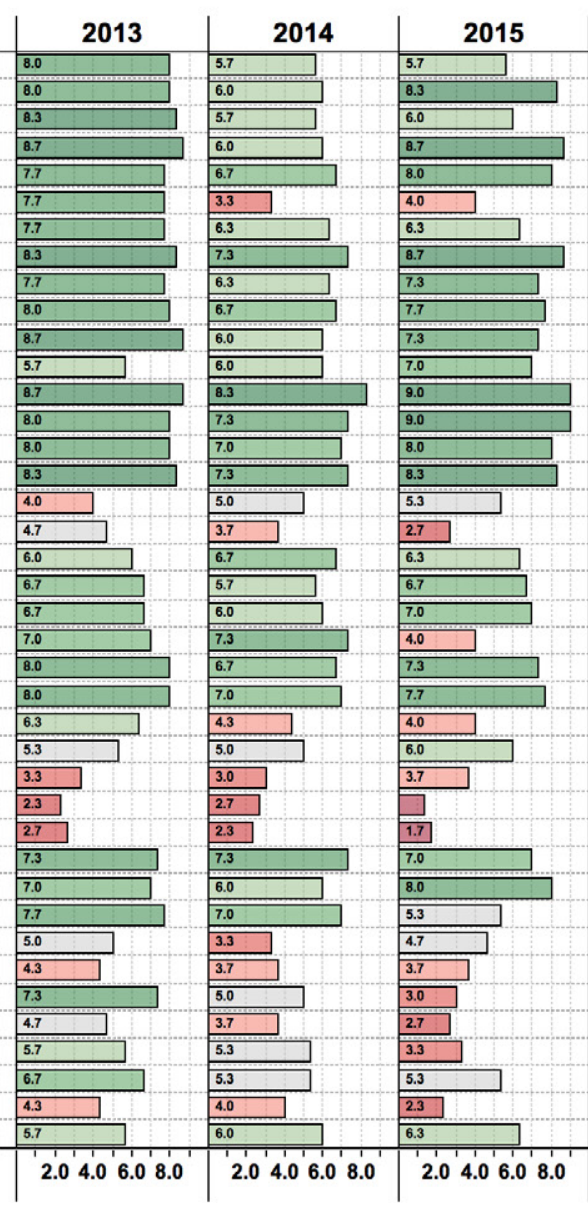

Fig. 2. Spring green-up and winter survival data collected from 2011 to 2015 at the Lake Wheeler Turfgrass Field Laboratory in Raleigh, NC. The horizontal axis is separated within years, and the colors indicate the average spring green-up or winterkill values increasing from 1 (red) to 9 (green), where 1 represents the lowest rating and 9 represents the highest. Mean separation between entries and years was based on Fisher's protected LSD $(\alpha=0.05)$. Values $\leq 1.5$ are not labeled.

was the highest in 2011 (7.33); PI 647879, PI 615161, and PI 289922 were the highest in 2013 (6.04); PI 255447 was the highest in 2014 (5.7); and PI 290905, PI 647879, and PI 289923 were the highest in 2015 (7.33). For the controls, spring green-up adjusted means across years ranked the cultivars as Patriot $>$ Tifsport $>$ Quickstand $>$ Tifway. Patriot had the greatest spring green-up in 2011 and 2014, Tifsport and Tifway had the greatest spring green-up in 2013, and Tifsport had the greatest spring green-up in 2015. Comparing the PIs and the entries, none were greater than the best-performing controls $(p>$ $0.05)$, although differences were seen between the topperforming PIs and some of the controls within years. PI 647880 had a higher rating than Tifsport, Quickstand, and Tifway in 2011; PI 647879, PI 615161, and PI 289922 had higher ratings than Quickstand in 2013; PI 255447 had a higher rating than Tifway in 2014; and PI 290905, PI 647879, and PI 289923 had higher ratings than Patriot, Quickstand, and Tifway in 2015 ( $p \leq 0.05)$.

For winter survival, PI 290905, PI 647879, PI 255447, PI 289923, and PI 615161 were the top-performing genotypes across years, showing great consistency (Fig. 2), although PI 647879, PI 291981, PI 647880, PI 286584, PI 491560, and PI 647881 had the highest winter survival of the PIs tested in 2011 (9.0); PI 647879, PI 615161, and PI 289922 were highest in 2013 (8.7); PI 289922 was highest in 2014 (8.3); and PI 299923 and 289922 were highest in 2015 (9.0). For the controls, winter survival adjusted means across years ranked the cultivars as Patriot $>$ Tifsport $>$ Quickstand $>$ Tifway. Patriot had the highest winter survival in 2011 (8.7), Tifsport and Tifway were highest in 2013 (8.0), and Tifway was highest in 2014 (7.0) and 2015 (7.7). Comparing PIs and controls, none were greater than the highest performing controls $(p>0.05)$, although differences were seen between the top-performing PIs and some of the controls within years. PI 647879, PI 291981, PI 647880, PI 286584, PI 491560, and PI 647881 had superior winter survival to Tifsport, Quickstand, and Tifway in 2011; PI 647879, PI 615161, and PI 289922 had a higher winter survival than Quickstand in 2013; PI 289922 had a higher winter survival than Patriot, Tifsport, and Quickstand in 2014; and PI 299923 
and 289922 had a higher winter survival than Patriot, Tifsport, and Quickstand in 2015.

\section{Controlled-Environment Freeze Evaluations and Field Correlations}

The data collected and analyzed for the freezing evaluations had significant Type III effects according the Wald $\chi^{2}$ test for the main effects of genotype and temperature; however, the interaction between them was not included in the stepwise selection. Further evaluation of the model shows high concordance and predictability of survival based on the data collected (Supplemental Table S1). Since Patriot had the highest reported freezing tolerance (Anderson et al., 2003, 2007), maximum likelihood estimates were calculated using Patriot as the reference entry for discerning differences in freezing tolerance (Table 3). PI 212293 was 1.63 times more likely to survive than Patriot, PI 290813 was 1.47 times more likely to survive than Patriot, and PI 290872 was 1.31 times more likely to survive than Patriot, when all other genotypes were held constant (Table 3). Using the estimates from Table 3, $\mathrm{LT}_{50}$ values were calculated for comparison with the field-based data (Table 4). When compared with spring green-up, $\mathrm{LT}_{50}$ temperatures had a significant Pearson's $r$ of -0.26 , suggesting that when spring green-up values increase, $\mathrm{LT}_{50}$ temperatures are decreasing. Similarly, for winter survival, the $\mathrm{LT}_{50}$ values had a significant correlation with winter survival means (Pearson's $r=-0.24$ ), suggesting that $\mathrm{LT}_{50}$ values decrease with increasing winter survival ratings. These correlations are based on adjusted means across years. When comparing $\mathrm{LT}_{50}$ and spring green-up and $\mathrm{LT}_{50}$ and winter survival within years, 2013-2014 and 2014-2015 showed the highest correlations. In 20132014, significant correlations were observed for spring green-up and winter survival of -0.26 and -0.33 , respectively. Correlations in 2014-2015 were -0.33 and -0.38 for spring green-up and winter survival, respectively.

\section{DISCUSSION}

The strong year $\times$ genotype effect is emphasized by the differences seen among years in the daily low averages and days below freezing counts. Based on the winter weather information (daily low averages and days spent below freezing) and evaluations of the entries (spring green-up and winter survival data), inferences can be made regarding the type of winter in each year and the effect it had on each genotype. Given that cold hardiness in the first year of growth reflects the establishment rate of each genotype (Ahring et al., 1975; Anderson et al., 2002) and 2011 experienced the greatest number of days below freezing, it is likely that ratings in this year are reflective of the total plot coverage prior to the winter months. Including establishment data would have confirmed this argument. In 2011-2012, plots were not subjected to a
Table 3. Maximum likelihood estimates from laboratory evaluations used to calculate the lethal temperature for $50 \%$ death $\left(\mathrm{LT}_{50}\right)$ for the intercept, genotypes, and for the temperature range $\left(-4\right.$ to $\left.-6{ }^{\circ} \mathrm{C}\right)$ from freezing data collected at the USDA-ARS station in Raleigh, NC, in 2016.

\begin{tabular}{lrrc}
\hline Parameter & Estimate† & Wald $\chi^{2}$ & $P>\chi^{2}$ \\
\hline Intercept & 10.23 & 194.00 & $<0.0001$ \\
T-643 & -0.65 & 2.56 & 0.1096 \\
T-730 & -0.47 & 1.30 & 0.2535 \\
T-732 & 0.06 & 0.02 & 0.8784 \\
T-734 & -0.83 & 4.32 & 0.0376 \\
T-737 & -0.97 & 5.80 & 0.0161 \\
PI 212293 & 1.63 & 8.37 & 0.0038 \\
PI 224141 & -0.14 & 0.11 & 0.7406 \\
PI 224143 & -0.64 & 2.46 & 0.1168 \\
PI 246600 & -0.29 & 0.51 & 0.4764 \\
PI 251809 & 0.38 & 0.77 & 0.3798 \\
PI 255447 & -0.12 & 0.08 & 0.7794 \\
PI 286584 & -0.47 & 1.30 & 0.2535 \\
PI 289922 & -0.50 & 1.55 & 0.2125 \\
PI 290813 & 1.48 & 8.28 & 0.004 \\
PI 290872 & 1.31 & 7.43 & 0.0064 \\
PI 290897 & -0.81 & 3.96 & 0.0465 \\
PI 290905 & 0.25 & 0.34 & 0.5579 \\
PI 291981 & -0.67 & 2.66 & 0.1027 \\
PI 491560 & -0.29 & 0.51 & 0.4764 \\
PI 647879 & 0.44 & 1.04 & 0.309 \\
Tifway & -0.29 & 0.51 & 0.4764 \\
Temperature & 1.85 & 180.70 & $<0.0001$ \\
\hline T Patitwas & & &
\end{tabular}

† Patriot was used as a reference level to calculate estimates. Intercept and temperature were treated as continuous variables. The data collected from $-7^{\circ} \mathrm{C}$ were not included due to complete mortality.

Table 4. Lethal temperature for $50 \%$ death $\left(\mathrm{LT}_{50}\right)$ for each entry according to estimates from the logistic regression analysis of data collected at the USDA-ARS station in Raleigh, NC, in 2016.

\begin{tabular}{lc}
\hline Genotype & $\mathrm{LT}_{50} \dagger$ \\
\hline & ${ }^{\circ} \mathrm{C}$ \\
T-737 & -5.01 \\
T-734 & -5.09 \\
PI 290897 & -5.10 \\
PI 291981 & -5.18 \\
T-643 & -5.19 \\
PI 224143 & -5.20 \\
PI 289922 & -5.27 \\
T-730 & -5.29 \\
PI 286584 & -5.29 \\
PI 246600 & -5.38 \\
PI 491560 & -5.38 \\
Tifway & -5.38 \\
PI 224141 & -5.47 \\
PI 255447 & -5.48 \\
T-732 & -5.58 \\
PI 290905 & -5.70 \\
PI 251809 & -5.80 \\
PI 647879 & -5.80 \\
Patriot & -6.08 \\
PI 290872 & -6.30 \\
PI 290813 & -6.34 \\
PI 212293 & -6.42 \\
\hline T LT & \\
\hline
\end{tabular}

$\dagger \mathrm{LT} \mathrm{T}_{50}$ values sorted from highest to lowest freezing temperature. 
harsh winter as indicated by the highest overall average temperature for that winter. The consistently higher temperatures in 2012-2013, compared with 2011-2012, allowed for moderate spring green-up but overwhelmingly high winter survival values. In 2013-2014, the coldest temperatures on average during the experimental period were recorded, and the overall lowest spring green-up and winter survival were also recorded. However, this year did not show the strongest correlations between spring green-up and winter survival when compared with the $\mathrm{LT}_{50}$ values collected in the freezing tests. This year may offer some insight into the potential survivability of each genotype in colder temperatures in locations at greater latitudes or elevations than Raleigh. Lastly, the 20142015 temperatures suggest a possible deacclimation event in the latter part of the winter. Temperatures throughout the early part of the winter were consistent with previous years and reflected in spring green-up values, although winter survival may be a result of freezing occurring after the entries emerged from dormancy. The correlations between spring green-up and winter survival and the $\mathrm{LT}_{50}$ values collected in the freezing tests were strongest in this year, providing further evidence that selections for spring green-up and winter survival could be made on the basis of the freezing tests alone.

Given the variable winters experienced during the experimental period, recommendations can be made regarding cold hardiness of the entries for winters in the Raleigh area, the potential cold hardiness of entries at higher latitudes or elevations, and the reaction of entries to deacclimation events. From a plant breeding perspective, the addition of top-performing bermudagrass PIs into a program focused on cold hardiness is bolstered by the consistent ranking in both winter survival and spring green-up and their comparison with the controls. Previous work denotes a higher relative freeze tolerance of Patriot compared with Tifsport, Tifway, and Quickstand (Anderson et al., 2002, 2003, 2007). Therefore, materials with consistently higher spring green-up and winter survival than the highest performing control (Patriot) would be considered relatively cold hardy.

Similar to field performance, the $\mathrm{LT}_{50}$ values calculated for Patriot and Tifway in this study reflect those previously reported by Anderson et al. (2002). Correlations identified here between the field evaluations and controlled environment, although relatively low, suggest that these $\mathrm{LT}_{50}$ values reflect cold hardiness of the genotypes in the field. There are a number of environmental factors outside of winter stress that could have resulted in these low correlations. For instance, plots were evaluated a single time for spring green-up and winterkill in late spring, but other evaluations and weather conditions like disease, moisture content, snow accumulation, and temperature fluctuations play an important role in winter survivability. Prior to this study, correlations between field and controlled freezing tests had only been recorded in zoysiagrass (Dunn et al., 1999; Patton and Reicher, 2007; Hinton et al., 2012). Larger controlled freezing experiments and more comparisons with field-based evaluations may help elucidate the connection between variable years and weather conditions during the winter months. Mainly, having higher correlations and therefore prediction accuracy between the field and controlled freezing tests would aid in prescreening plant materials for the field and provide an economic advantage for plant breeders.

The evaluation of these genotypes shows that a number of available PIs and accessions can help to improve cold hardiness and/or freeze tolerance not only in common bermudagrass for development of seeded cultivars, but also in common $\times$ African interspecific hybrids for the clonally propagated market. To date, the main source of cold hardiness materials for breeding has been associated with common-type bermudagrass (Wu et al., 2014), and the main comparisons of cold hardiness have been performed between seeded, common types, and interspecific hybrids (Anderson et al., 2002, 2003, 2007). To our knowledge, this is the first study focused on levels of freeze tolerance among African bermudagrass germplasm. The ability to select freeze-tolerant materials from the African pool could greatly improve the levels of freeze tolerance among hybrid breeding populations and ultimately released cultivars.

Overall, the evaluation of the common and African bermudagrass germplasm collection indicates that genotypes exhibiting greater cold hardiness and/or freeze tolerance than industry standards exist. The genotypes that showed the greatest cold hardiness were PI 290905, PI 647879, PI 255447, PI 289922, PI 289923, and PI 615161, which had consistently greater spring green-up and winterkill ratings than Patriot, Tifsport, Quickstand, and Tifway, though not always significantly. These materials can be used as additional sources of cold hardiness in bermudagrass breeding. Furthermore, the introduction of controlled, laboratory-based freezing tests in addition to field-based evaluations would further the efficiency of selection for this trait in bermudagrass breeding.

\section{Conflict of Interest}

The authors declare that there is no conflict of interest.

\section{Supplemental Material Available}

Supplemental material for this article is available online.

\section{Acknowledgments}

The authors wish to thank personnel at the Turfgrass Field Laboratory (Raleigh, NC) for help maintaining research plots. This research was supported in part by funding provided by the North Carolina Crop Improvement Association and the North Carolina State University Center for Turfgrass Environmental Research and Education. 


\section{References}

Ahring, R.M., W.W. Huffine, C.M. Taliaferro, and R.D. Morrison. 1975. Stand establishment of bermudagrass from seed. Agron. J. 67:229-232. doi:10.2134/agronj1975.00021962006700020014x

Ahring, R.M., and R.M. Irving. 1969. A laboratory method of determining cold hardiness in bermudagrass, Cynodon dactylon (L.) Pers. Crop Sci. 9:615-618. doi:10.2135/cropsci1969.0011 183X000900050031x

Anderson, J., C. Taliaferro, and D. Martin. 2002. Freeze tolerance of bermudagrasses. Crop Sci. 42:975-977. doi:10.2135/ cropsci2002.9750

Anderson, J.A., and C.M. Taliaferro. 2002. Freeze tolerance of seed-producing turf bermudagrasses. Crop Sci. 42:190-192. doi:10.2135/cropsci2002.1900

Anderson, J.A., C.M. Taliaferro, and D.L. Martin. 1993. Evaluating freeze tolerance of bermudagrass in a controlled environment. HortScience 28:955.

Anderson, J.A., C.M. Taliaferro, and D.L. Martin. 2003. Longer exposure durations increase freeze damage to turf bermudagrasses. Crop Sci. 43:973-977. doi:10.2135/cropsci2003.9730

Anderson, J.A., C.M. Taliaferro and Y.Q. Wu. 2007. Freeze tolerance of seed and vegetatively-propagated bermudagrass compared with standard cultivars. Appl. Turfgrass Sci. 4(1). doi:10.1094/ATS-2007-0508-01-RS

Beard, J.B. 1973. Turfgrass: Science and culture. Prentice Hall. Englewood Cliffs, NJ.

DiPaola, J.M., and J.B. Beard. 1992. Physiological effects of temperature stress. In: D.V. Waddington, et al., editors, Turfgrass. ASA Monogr. 32. ASA, CSSA, and SSSA, Madison, WI. p. 231-267. doi:10.2134/agronmonogr32.c7

Dunn, J.H., S.S. Bughrara, M.R. Warmund, and B.F. Fresenburg. 1999. Low temperature tolerance of zoysiagrasses. HortScience 34:96-99.

Gatschet, M., C. Taliaferro, J. Anderson, and V. Baird. 1994. Improving bermudagrass tolerance to winter stress. Golf Course Manage. 62:52-55.

Giolo, M., S. Macolino, E. Barolo, and F. Rimi. 2013. Stolon reserves and spring green-up of seeded bermudagrass cultivars in a transition zone environment. HortScience 48:780-784.

Hinton, J.D., D.P. Livingston, G.L. Miller, C.H. Peacock, and T. Tuang. 2012. Freeze tolerance of nine zoysiagrass cultivars using natural cold acclimation and freeze chambers. HortScience 47:112-115.
Kimball, J.A., T.D. Tuong, C. Arellano, D.P. Livingston, and S.R. Milla-Lewis. 2017. Assessing freeze-tolerance in St. Augustinegrass: temperature response and evaluation methods. Euphytica 213:110. doi:10.1007/s10681-017-1899-z

Munshaw, G.C., E.H. Ervin, C. Shang, S.D. Askew, X. Zhang, and R.W. Lemus. 2006. Influence of late-season iron, nitrogen, and seaweed extract on fall color retention and cold tolerance of four bermudagrass cultivars. Crop Sci. 46:273-283. doi:10.2135/cropsci2005.0078

NRCS. 2013. Web soil survey. USDA Nat. Resour. Conserv. Serv. http://websoilsurvey.sc.egov.usda.gov/ (accessed 2013).

NTEP. 2012. Bermudagrass results from 2007-2012. Natl. Turfgrass Eval. Progr. https://ntep.org/ntep/bg.htm (accessed 2013).

Patton, A.J., and Z.J. Reicher. 2007. Zoysiagrass species and genotypes differ in their winter injury and freeze tolerance. Crop Sci. 47:1619-1627. doi:10.2135/cropsci2006.11.0737

Patton, A.J., M.D. Richardson, D.E. Karcher, J.W. Boyd, Z.J. Reicher, J.D. Fry, et al. 2008. A guide to establishing seeded bermudagrass in the transition zone. Appl. Turfgrass Sci. 5(1). doi:10.1094/ATS-2008-0122-01-MD

Richardson, M.D., J.T. Brosnan, and D.E. Karcher. 2014. Turfgrass winterkill observations from the transition zone. Appl. Turfgrass Sci. 11(1). doi:10.2134/ATS-2014-0049-BR

Rimi, F., S. Macolino, M.D. Richardson, D.E. Karcher, and B. Leinauer. 2013. Influence of three nitrogen fertilization schedules on bermudagrass and seashore paspalum: 1. Spring green-up and fall color retention. Crop Sci. 53:1161-1167. doi:10.2135/cropsci2012.09.0562

Rutledge, J.M., C.H. Peacock, R.J. Cooper, and A.H. Bruneau. 2009. Comparative cold tolerance of selected bermudagrass (Cynodon Spp.) cultivars. Int. Turfgrass Soc. Res. J. 11:829835.

SAS Institute. 2013. The SAS system for Windows. Release 9.4. SAS Inst., Cary, NC.

Taliaferro, C.M. 1995. Diversity and vulnerability of Bermuda turfgrass species. Crop Sci. 35:327-332. doi:10.2135/cropsci1 995.0011183X003500020006x

Taliaferro, C.M., D.L. Martin, J.A. Anderson, M.P. Anderson, and A.C. Guenzi. 2004. Broadening the horizons of turf bermudagrass. Turfgrass Environ. Res. Online 3:1-9.

Wu, Y., D.L. Martin, C.M. Taliaferro, J.A. Anderson, and J.Q. Moss. 2014. 'Latitude 36 Turf Bermudagrass'. US Plant Patent 2471P3. Date issued: 25 February. 